\title{
The Stories of Logics
}

\author{
Andreas Kapsner \\ Munich Center for Mathematical Philosophy \\ Ludwig-Maximilians-Universität, München \\ Andreas.Kapsner@lrz.uni-muenchen.de
}

\begin{abstract}
In this paper, I investigate in how far we can use fictional stories to learn about logic. How can we engage with fiction in order to come to find out what logical principles are actually valid? Is that possible at all? I claim that it is, and I propose two case studies to make the point.
\end{abstract}

\section{Introduction}

In this paper, I would like to explore in how far we can use fictional stories to learn about logic. ${ }^{1}$ To give it away from the start, I'd like to suggest that, indeed, there is much to learn about logic from fiction.

There might be two ways in which this claim might be understood, and I find both interesting, though I will only investigate one of them. First, we might ask how we can devise stories that teach logic, so that students and others may learn correct reasoning from them. Or, to set a somewhat less ambitious goal, how we can couch particular reasoning tasks in stories that make the readers more likely to draw correct inferences (whether or not they consciously learn something about logical reasoning in the process). These questions are at the moment investigated by researchers in Amsterdam, Edinburgh and elsewhere,

\footnotetext{
${ }^{1}$ This paper has been, for several reasons, been on its way to publication for many years. Some of its ideas draw on Pietz (2010), a paper so old that even my name has changed in the meantime. Manuscripts that contain most major ideas of this piece have been floating around since 2015. In the time it took to bring this manuscript to publications, many articles have appeared that touch on related themes, such as Wildman and Folde (2017), Proudfoot, D. (2018), Estrada González (2018), Badura, C., Berto, F. (2019) and Berto, F., Jago, M. (2019). (Indeed, Estrada González cites my manuscript under a former title, "Logic, Fiction, Falsity", and notes that reading it brought him to think about the topic in the first place). I still stand by all that I write in this piece, but had I read these works before writing the article, I would have framed my ideas quite differently. I make some remarks on some of these pieces in footnotes, but I have decided to leave the original structure of my arguments intact.
}

Australasian Journal of Logic (16:4) 2019, Article no. 1 
and though not all of their results have been published yet, their project is fascinating and seems to be a successful one. ${ }^{2}$

The question, however, that I want to focus on here is a different (and in a sense more fundamental) one. How can we, as philosophers and logicians, use stories to come to find out what logical principles are actually valid and which aren't? Is that possible at all?

I want to claim that it is, at least to some degree. It will turn out that it is hard to learn from stories what the one true logic (should it exist) is. Rather, stories can cast doubt on or lend support to particular logical principles, and thus speak for or against whole classes of logics. Therefore, I will propose to look at two case studies that revolve around two important logical principles, the Law of Excluded Middle $(\vDash A \vee \neg A)$ and the Law of Explosion $(A \wedge \neg A \vDash B)$. Between the two principles, a lot of logical ground is covered, but they are also related to each other. They are, in a certain sense, dual principles, as will become clear in the course of this essay. Both are classically valid and have been challenged by non-classical logicians, and I'll explore whether and how the different camps can use stories to make their case. As the party defending the principles is, in such discussions, most often adhering to classical logic, I sometimes talk about them as "classical logicians", with apologies to those non-classical logicians who defend logics in which these principles are valid and which find their differences with classical logic in other places.

Each of the two principles will be explored through its own story. The first story is one about a quite bland character called Jones. Though not too exciting as a story, I promise to you that it has a surprising twist that makes it worthwhile: Even though it was intended to make a case for a certain logic, on closer inspection it turns out to point in a somewhat different direction.

The second story is of a more exciting quality, involving, as it does, intriguing and even impossible events. Again, it was told by an author with a logical agenda, this time to argue for paraconsistency, i.e. the failure of the Law of Explosion. And again, I will argue that the upshots of the story are not exactly what the author had intended, though in this case I argue that the case of the author is, in a sense, stronger than he himself had realized.

\section{Excluded Middle}

We'll start with some quite general observations about fiction that have some bearing on the Law of Excluded Middle.

Law of Excluded Middle $\vDash A \vee \neg A$

\footnotetext{
${ }^{2}$ See Achourioti et al. (2014).
} 
One reason why thinking about fictions might be interesting for a philosophical logician who is open to explore non-classical systems is the following: In asking what is to be considered true and what false in a given fiction, we may find ourselves pushed towards a many-valued system, in particular one in which there is room for a truth value gap. To illustrate this thought, we need not take recourse to any tailor-made story, pretty much any piece of conventional fiction will do.

Consider, for example, Sherlock Holmes and Dr. Watson in The Adventure of the Speckled Band. ${ }^{3}$ The story starts with both of them awakened one very early moring in the April of 1883 by a lady in distress. The story says nothing of the day before, but of course we are free to wonder how they spent it. In particular, is it true (or, in case you are bothered by this way of talking, true-in-the-story) that they dined together that day? It seems clear that we can't say that. Well, should we conclude from that that it is false that they had dinner together? If we say that, then we seem to be obliged to say that it is true that they didn't have dinner together that day. But saying that seems as unwarranted as the earlier claim.

At least on first blush the most natural thing here is to say that it is neither true nor false in the story that they had dinner together. And the most natural thing for a logician to do in such a situation is to reach for a third truth value, neither-true-nor-false, to assign to statements. ${ }^{4}$ We are thus already in the realm of non-classical logics, more precisely we are thinking about many-valued logics, more precisely still of many-valued logics with truth value gaps. ${ }^{5}$

There are many ways a logic with gaps can be set up, and what we have said so far does not point to any one of them in particular. I will give, in order to illustrate the phenomenon, one such logic, without wanting to make any claim against rival gappy accounts. We will consider what is known as Strong Kleene logic, or K3. In K3, we find three truth values, the classical $\mathcal{T}$ (true) and $\mathcal{F}$ (false), as well as the gappy value $\mathcal{N}$ (neither-true-nor-false). The values of complex statements are given by the following truth tables:

K3:

\begin{tabular}{|c||c|}
\multicolumn{1}{c|}{} \\
\hline \hline $\mathcal{T}$ & $\mathcal{F}$ \\
\hline $\mathcal{N}$ & $\mathcal{N}$ \\
\hline $\mathcal{F}$ & $\mathcal{T}$ \\
\hline
\end{tabular}

\begin{tabular}{|c||c|c|c|}
\multicolumn{1}{c||}{} & $\mathcal{T}$ & $\mathcal{N}$ & $\mathcal{F}$ \\
\hline \hline $\mathcal{T}$ & $\mathcal{T}$ & $\mathcal{N}$ & $\mathcal{F}$ \\
\hline $\mathcal{N}$ & $\mathcal{N}$ & $\mathcal{N}$ & $\mathcal{F}$ \\
\hline $\mathcal{F}$ & $\mathcal{F}$ & $\mathcal{F}$ & $\mathcal{F}$ \\
\hline
\end{tabular}

\begin{tabular}{|c||c|c|c|}
\cline { 2 - 3 } \multicolumn{1}{c||}{} & $\mathcal{T}$ & $\mathcal{N}$ & $\mathcal{F}$ \\
\hline \hline $\mathcal{T}$ & $\mathcal{T}$ & $\mathcal{T}$ & $\mathcal{T}$ \\
\hline $\mathcal{N}$ & $\mathcal{T}$ & $\mathcal{N}$ & $\mathcal{N}$ \\
\hline $\mathcal{F}$ & $\mathcal{T}$ & $\mathcal{N}$ & $\mathcal{F}$ \\
\hline
\end{tabular}

In many-valued logics, consequence is defined by way of a subset of the values called the designated values: An inference is valid iff in every valuation in which

\footnotetext{
${ }^{3}$ It seems to mean bad luck to write a paper about the philosophy of fiction that does not use Holmes as an example. I don't know what would happen if one did, nor do I know whether anyone at all knows this, but I don't care to be the one to find out.

${ }^{4}$ Or to stick with two values and allow for some statements to receive neither value, which for the purposes of determining logical consequence amounts to the same thing in most cases.

${ }^{5}$ For a different use of many-valued logics for an account of fiction see Woods (2009).
} 
all of the premises receive a designated value, the conclusion receives a designated value as well. In the case of K3, the only designated value is $\mathcal{T}$. It isn't hard to see that $\vDash A \vee \neg A$ is not valid in K3, just take $A$ to be $\mathcal{N}$.

Now, we seem to have a strong case for truth value gaps, ${ }^{6}$ and we have a plausible gappy logic that does not validate the Law of Excluded Middle. Are we there yet and have we decided the case for the party that doubts the Law of Excluded Middle?

Actually, it isn't all that clear, as there are several ways in which to view this matter that come to a different conclusion, one of which I will spell out here:

Here is something rather plausible that a defender of the LEM might say: Granted, "Holmes and Watson had dinner the night before the adventure of the speckled band commenced" seems to be neither true nor false. But we could easily extend the fiction to settle this question. Arthur Conan Doyle did not mean to write a story about a world in which there are truth value gaps. He wanted to write a story about a normal world (at least in this respect). He just couldn't write a story long enough to pin everything down. This is obviously impossible, but if we are interested in a particular question, we can help him out. We might rewrite the story in such a way that they did have dinner, and we might rewrite it in ways in which they did not have dinner. But in each and every case, "Holmes and Watson had dinner the night before the adventure of the speckled band commenced, or they did not" will come out true. We don't know which of the disjuncts is true in the original story, but there is no way we could flesh out the story that will make the disjunction false. We should thus conclude that the disjunction is true already in the story itself. How couldn't it be? And this seems to be true for other instances of the LEM, which in turn suggest we should accept it as valid.

In terms of logical machinery, this brings us to the idea of supervaluations. To put it informally, ${ }^{7}$ a supervaluation considers all the ways of "filling in the gaps" of the story. It proclaims an inferece valid if and only if: If if all the premises are true in all the ways in which the gaps are filled, then the conclusion is also true in all the ways in which the gaps are filled. In particular, $\vDash A \vee \neg A$ is supervaluationally valid, because it is true in all the ways in which we may flesh out the story, as we have observed above. ${ }^{8}$

\footnotetext{
${ }^{6}$ As an interesting sideline, let me note that this application clearly seems to defeat Dummett's claim that such many-valued logics should be thought of as simply describing different ways of being true or false: According to him, the designated values all depict ways in which a statement can be true, while the undesignated values all show us different ways of being false (See Dummett (1978), p. 14. For discussion, see Kapsner (2014), p. 67 ff.). While, arguably, that idea might have had some merit in the cases of presupposition failure (eg. "The present king of France is bald") that prompted Dummett's discussion, it seems clearly the wrong way to think about our dinner case. It is not false that they had dinner, neither in the way "Holmes and Watson were awakened by an elephant in distress" is false nor in any other way; it is just left open by the fiction.

${ }^{7}$ For a more formal treatment, see Priest (2008), p. 133.

${ }^{8}$ I'm grateful to the reviewer for pointing me to Varzi (1997), who discusses such supervaluational solutions to problems in fiction (including the problem of inconsistent stories that is
} 
For sure, there may be ways for the critic of the Law of Excluded Middle to dig in her heels against this line of reasoning, but let us take this as a chance to leave the world of everyday fiction and get our hands dirty with some custom made stories. In this case, it brings us to the tale of the late Mr. Jones.

\section{$3 \quad$ Bravery in Logic}

When Jones died, behind him lay an orderly and satisfying life. It may have been rather uneventful, but no one, and certainly not a philosopher, should jump to the conclusion that it therefore was dull and boring. What is certain, however, is this: Jones never went to war, never even got into a serious fight, he was never present when a rabid dog fiercely attacked a child, and he was never faced with the question whether he should run into a burning house to save the inhabitants. In fact, he never got into any kind of situation in which he could have displayed brave behavior, or, for that matter, have failed to display such behavior. And even death itself came to him mercifully and quite unexpectedly in his sleep, after which he was cremated and his ashes were strewn in the wind.

And ... that was it. As I promised above, the second story will be better. ${ }^{9}$ But bear with me, there's something of interest to be learned even here.

To see how one could possibly learn anything about logic from this superbly anti-climatic story, consider this question: Was Jones, according to the story, ${ }^{10}$ a brave man? Or was he not brave? You might feel a certain reluctance to answer "yes" to either of these questions. More, you might even feel that someone who would answer either question in the affirmative would not have fully understood this story. Normally, we can not tell whether someone is brave or not until we watch them getting themselves into a dangerous situation. Only then will their bravery or cowardice become apparent. But as Jones is now dead and the story over, we will not come to observe him in such a situation.

But this presents an embarrassment of sorts to someone who, as for example a classical logician, believes in the validity of the Law of Excluded Middle. A classical logician would seem to be committed to "Either Jones was brave, or he was not brave", but at least on Michael Dummett's account, who first introduced

\footnotetext{
the focus of the second part of this paper).

${ }^{9}$ You might even be reluctant to call this a story and prefer to call it a (not very elaborate) thought experiment. The line between story and thought experiment seems to me not to be a sharp one, and even the criteria seem unclear (it's not about length, at least if you're willing to call the following, often attributed to Hemingway, a story: "For sale: baby shoes, never worn.").

In any case, I could elaborate on the tale to the point where most would be willing to call it a story, unless one holds that an exciting story arc is an essential feature of any story; it is quite crucial that nothing exciting happens, at least to Jones.

${ }^{10} \mathrm{I}$ will leave off such qualifiers from now on.
} 
us to Jones and his sedate life, ${ }^{11}$ this is something we should be reluctant to assert.

Now, notice the difference between this failure of the Law of Excluded Middle and the one we discussed above. Here, the story is deliberately constructed in such a way to convey that it can't be known whether Jones was brave or not. ${ }^{12}$ Nothing in the Holmes story, in contrast, suggested that it couldn't be known whether Holmes and Watson had dinner together.

Instead, Dummett suggested that we should employ a logic in which the Law of Excluded Middle fails, namely intuitionistic logic. Not only is it non-classical, intuitionistic logic also can't be seen as a finitely many valued logic. ${ }^{13}$ Intuitionistic logic was developed as a logic for constructive mathematics. The main idea of constructive mathematics is that mathematical statements are not describing a platonic reality that is independent of us. Rather, a mathematical statement can only be correctly asserted if it has a proof, and we may not assume that every statement or its negation has a proof.

Dummett's project was to bring this (very subtle, and here admittedly rather inadequately summarized) set of ideas to statements beyond mathematics, such as the statement "Jones was brave". As we observed above, in the story there is no proof (or verification, as empirical proofs are often referred to) for "Jones was brave", and neither is there a proof for "Jones was not brave"14. Thus, with Dummett, we should want to conclude that we cannot assert the statement "Jones was brave", nor the statement "Jones was not brave". More, I think that we should be inclined to say that we know that no one will ever be able to verify either statement, even if we allow that to include persons and their future experiences in the story world itself. Given that we know that Jones definitely never was in danger and that, for example, no one will be able to dissect his brain to find some structures predisposing him to brave actions (we might, in the story, have technology that allowed us to do something like this, but remember that I made sure that his ashes are gone with the wind), that conclusion seems hard to resist.

\footnotetext{
${ }^{11}$ Dummett (1978), p.14 ff. The above story is not a quote but rather my own retelling of Dummett's tale. It is, to be honest, not even totally clear to me that he is thinking about a story and not just a "normal" thought experiment. Dummett talks about two characters who have an argument about Jones, where Jones in turn was "imagined" by the first character.

${ }^{12}$ The reviewer suggested that we might want to respond to this by resorting to some sort of epistemicism about bravery (see Williamson 1994b). Epistemicism is quite at odds with Dummett's general philosophy of language, and a satifying solution along those lines might thus be seen as a deep repudiation of the whole project. However, I bleieve that explicitly presenting the Jones case as a fiction makes an epistemicist solution rather unappealing. Had Jones been a real person, epistemicism might have had some allure: maybe, somehow he might have been brave and we might have no way to know it. But that there should be a matter of fact about the story that settles the question without us being able to come to know it seems far-fetched to me.

${ }^{13}$ See Priest 2008, p. 137.

${ }^{14}$ Or so it would seem... If suspense is not what you're looking for in papers about fiction, take a peek at the next section heading.
}

Australasian Journal of Logic (16:4) 2019, Article no. 1 


\section{Actually, Jones was not brave (at least intu- itionistically)}

In truth, though, the road from Jones to intuitionistic logic is not as straight as the last section made it look. In fact, it might lead somewhere else altogether.

Here's the problem: Consider the statement "Jones was not brave". What would it take for this to be true? We should expect, both intuitively and on account of how this statement features in Dummett's argument, the following: According to the constructive way of explaining things, Jones would have had to encounter a dangerous situation and behave in a cowardly fashion. That would be a situation that falsifies "Jones was brave". As there were no such statements, we can't assert the statement "Jones was not brave".

But here is what the intuitionistic account actually tells us: To prove a negated statement, it is enough to assume it's truth and deduce a contradiction. ${ }^{15}$ This is quite a natural idea in mathematics. Assume that you can prove that $\mathrm{x}$ is the greatest prime number. Then Euclid, by way of his ingenious proof, shows you how to construct an even larger prime number. Assuming that $\mathrm{x}$ was the largest prime number, you thus deduce that it wasn't the largest prime number, a contradiction. So $\mathrm{x}$ was not the largest prime number, after all, and in fact, there is no largest prime number at all (since $\mathrm{x}$ was arbitrary).

But we concluded that Jones is dead and that there is no possibility of future technology reconstructing brain scans of his, etc.. In other words, no one will ever verify the statement "Jones was brave". In yet other words, we can verify "Jones was not brave". Why? Because we already have our contradiction from our assumption: The statement is verified (by assumption) and is not verified (because it cannot be verified).

The Kripke semantics for intuitionistic logic bear this out (see Kripke (1965)), and it is instructive to view the issue from this perspective.

The semantics is a variation of the well known possible worlds semantics of modal logics. The worlds are supposed to be information states that the inquisitive subject steps through in her quest of knowledge. As intuitionistic logic was conceived of as a logic for constructive mathematics, the worlds are normally taken to record what has been proven up to a certain point in time. Applied to empirical discourse, we normally speak of verifications instead of proofs. There is an accessibility relation on the worlds that has a strong temporal flavor: One stage comes literally after the other. Let us spell this out a bit more formally:

A model will be a structure, $[W, \leq, v]$, where $W$ is a non-empty set of worlds or information states, and $\leq$ is a binary relation on those worlds which is reflexive, transitive and anti-symmetric, that is, a partial order.

\footnotetext{
${ }^{15}$ Though close, this is not the definition of negation in intuitionistic logic, only a way of proving a negation. As a definition, it would be circular. Negation is defined via the deduction of $\perp$ from the assumption of the negated statement, where $\perp$ is a particularly absurd statement, such as $1=0$.
}

Australasian Journal of Logic (16:4) 2019, Article no. 1 
The valuation function $v$ assigns a truth value, 1 or 0 , to each atomic statement $p$ at each world. Intuitively, for $p$ to receive value 1 at a world means that that statement is proven at that world. For it to receive value 0 , on the other hand, means just that $p$ has not been proven (yet) at world $w$. It does not mean that $p$ has been disproven at world $w$. That is, if the investigation is carried on, we might well find a proof of $p$ at a later stage or world, and thus the value at that stage will turn to 1 . On the other hand, a proof is something definitive, such that a statement that is proven at a world will always remain proven at subsequent stages.

In the semantics, this thought is manifested in the so called heredity constraint:

For each $p$ : if $w \leq w^{\prime}$ and $v_{w}(p)=1$ then $v_{w^{\prime}}(p)=1$.

For $v_{w}(p)=1 \mathrm{I}$ will write $w \Vdash_{1} p$, and for $v_{w}(p)=0$ I will write $w \Vdash_{0} p$. I will also write $w \Vdash_{1} p$ for "not $w \Vdash_{1} p$ ", and likewise $w \Vdash_{0} p$. As the valuation functions are total, $w \Vdash_{0} p$ is equivalent to $w \Vdash_{1} p$.

Logical consequence is defined as the preservation of value 1 from premises to conclusions: If all the premises take value 1 in a valid argument, then so does the conclusion.

One can represent the models graphically; for example, here is a partial model that corresponds to our story:

\begin{tabular}{|c|c|c|c|c|c|}
\hline \multicolumn{1}{c|}{} \\
\hline \hline Jones led a quiet life & 1 & 1 & 1 & 1 & 1 \\
\hline Jones died in his sleep & 0 & 1 & 1 & 1 & 1 \\
\hline Jones's ashes dispersed & 0 & 0 & 1 & 1 & 1 \\
\hline Widow falls asleep & 0 & 0 & 0 & 1 & 0 \\
\hline Jones was brave & 0 & 0 & 0 & 0 & 0 \\
\hline
\end{tabular}

The worlds $w_{1}, w_{2}$ and $w_{3}$ record some of the things that become verifiable as the story unfolds. The perspective here is of a subject in the story world, who can find out different things about Jones as the information in the story becomes available to her. Worlds $w_{4}$ and $w_{5}$ represent two of the many ways in which the story might unfold further: In the first embellishment of the story, Jones's widow falls asleep during the memorial service, in the second, she does 
not (or maybe, Jones wasn't even married in that scenario). But neither in $w_{4}$ nor in $w_{5}$, the statement "Jones was brave" becomes verifiable, so it keeps being assigned value 0 . This, as I remarked above, is due to the intentionally chosen plot of the story, not to the particular choice of worlds in this illustrative example: No world after $w_{3}$ can ever assign value 1 to "Jones was brave", because in no world will it be verifiable that "Jones was brave".

Again, though, remember that "Jones was brave" receiving value 0 at a world does not mean that "Jones was not brave" is verifiable at that world. $w_{1}$, where we have not learned yet about the cremation and the fate of his ashes, assigns value 0 to "Jones's ashes dispersed", but it is not verifiable at that world that "Jones's ashes were not dispersed".

In order to find out what the intuitionist will say about a negated statement such as "Jones was not brave", we need to inspect the conditions that determine the semantic values of logically complex statements:

$$
\begin{aligned}
& \text { For all } w \epsilon W \text { : } \\
& w \Vdash_{1} A \wedge B \text { iff } w \Vdash_{1} A \text { and } w \Vdash_{1} B \\
& w \Vdash_{1} A \vee B \text { iff } w \Vdash_{1} A \text { or } w \Vdash_{1} B \\
& w \Vdash_{1} A \supset B \text { iff for all } x \geq w, x \Vdash_{0} A \text { or } x \Vdash_{1} B \\
& w \Vdash_{1} \neg A \text { iff for all } x \geq w, x \Vdash_{0} A
\end{aligned}
$$

The last clause, giving the semantics of negation, is the formal correlate of the thought we discussed above: ${ }^{16}$ That to verify $\neg A$, it is enough to make sure is that we will never verify $A$. And we know that if we could deduce a contradiction from such a hypothetical verification. In our case, the contradiction is simply between the fact that the story is set up in a way that precludes a verification of "Jones was brave" and the hypothetical verification of this statement. This brings us to our problematic result: As no matter how we enrich the simple model of the story, "Jones was brave" will remain at value 0 , we have to assign value 1 to "Jones was not brave". For the intuitionist, that is, "Jones was not brave" is true.

This is clearly a bad result, first because it simply seems to get wrong what we take "Jones was not brave" to mean, and second because it undermines Dummett's own argument for intuitionistic logic.

What to do? I see three options. First, the intuitionistic logicians might start to refine the translation from the mathematical realm in such a way that "assume a proof of a statement and deduce a contradiction" means something that does not apply to the case at hand. That does not seem very promising to me, but of course it might turn out to be feasible. ${ }^{17}$

Second, they might reject my retelling of the story, in which I have made it clear that no proof of Jones's bravery is to be had. They might opt for an

\footnotetext{
${ }^{16}$ I will not discuss the plausibility for the semantic clauses for the other connectives in this piece, but have done so elsewhere. (Kaspner (2014))

${ }^{17}$ See Williamson (1994) for further problems this approach will face.
} 
alternative ending in which Jones's brain is preserved in a jar, hinting at a possible future in which new technology is able to trace "bravery"-structures in that brain. In that story, the intuitionistic negation of "Jones was brave" is not provable any more, and so it might be a story that is a counterexample of the Law of Excluded Middle. I see two problems here: First, this now seems like one of the mundande failures of LEM that I discussed above when I mentioned the question of Holmes and Watson having dinner. Secondly, it simply seems utterly bizzarre to me to maintain that the story with the cremated Jones should not be a counterexample of LEM, while the one with the brain in the jar is.

To me, the most plausible option is the third one: Constructivists might supply a slightly different account of negation, one that is in better accord with empirical areas of discourse. I will discuss such an account in the next section and show how it can make use of the story about Jones to argue against LEM.

\section{Saving Jones's Honor by Choosing Better Se- mantics}

The idea for such a better account was something we already came across in the beginning of the last section. Instead of saying that $\neg A$ is verified by merely showing that a verification of $\mathrm{A}$ is impossible (by deducing a contradiction from its assumption), we should ask for something stronger. To verify $\neg A$, we need to be able to falsify A. That is, to verify "Jones is not brave", we should have to observe him behave decidedly un-bravely in a dangerous situation.

And, to make the picture complete: How do you falsify $\neg A$ ? The most natural answer is, of course: By verifying A! To falsify "Jones was not brave", we again need to observe a dangerous situation and see him acting courageously.

But here is, finally, the promised surprising twist of the story: This move will not give us intuitionistic logic! Famously, intuitionistic logic not only fails to validate the Law of Excluded Middle, but also Double Negation Elimination. ${ }^{18}$

\section{Double Negation Elimination $\neg \neg A \vDash A$}

On the other hand, it is pretty straightforward to see that the account of negation in terms of falsifications leads us to a logic that actually validates Double Negation Elimination: If you can verify $\neg \neg A$, then that means that you can falsify $\neg A$, and that means that you can verify $A$.

\footnotetext{
${ }^{18}$ An easy intuitionistic countermodel for both Double Negation Elimination and the Law of Excluded Middle:

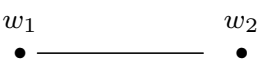

Let $w_{1} \Vdash_{0} A$ and $w_{2} \Vdash_{1} A$.
} 
By giving suitable verification and falsification conditions for the other connectives as well, these ideas can be extended to a logical system quite nicely. There are several options, but a likely outcome is that one ends up with what is known as Nelson logic. ${ }^{19}$ For illustrative purposes, I present the Kripke semantics of the Nelson logic $N_{3}$ (we will meet its cousin $N_{4}$ later in this piece).

A model for $N_{3}$ is once again a structure[W, $[, v], W$ being a non-empty set of partially ordered $(\leq)$ worlds and $v$ a valuation function from formulas to 1 and 0 . Worlds are again intuitively to be understood as stages of investigation, and the accessibility relation marks that one stage is an epistemically possible development from one stage to another.

This time, though, we give both of the values 1 and 0 a substantive reading: 1 stands for "verifiable", 0 for "falsifiable". This is in contrast to the semantics of intuitionistic logic, in which one of the values marked the constructive notion and the other the mere absence of that notion.

Moreover, for $N_{3}$ we allow $v$ to be a partial function, so that statements might not receive either value at a given world. This reflects the fact that at a stage of investigation, a statement might be neither verifiable nor falsifiable. Note that $w \vdash_{0} p$ is not equivalent to $w \Vdash t_{1} p$ any more, and that the same of course goes for $w \Vdash_{1} p$ and $w \Vdash t_{0} p$.

We assume that verifications and falsifications are conclusive, and therefore we will have hereditary constraints for both 1 and 0 :

For all $p$ and all worlds $w$ and $w^{\prime}$, if $w \leq w^{\prime}$ and $w \Vdash_{1} p$, then $w^{\prime} \Vdash_{1} p$, and

for all $p$ and all worlds $w$ and $w^{\prime}$, if $w \leq w^{\prime}$ and $w \Vdash_{0} p$, then $w^{\prime} \Vdash_{0} p$.

Logical consequence is, as before, defined in terms of preservation of value 1 .

To illustrate, here is an example with the same world-structure as before:

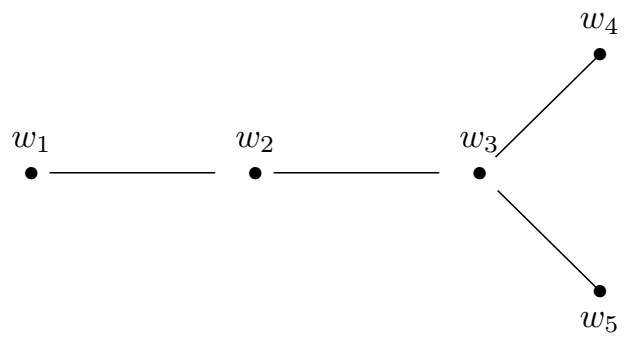

Here is a valuation that suits the requirements of $N_{3}$ and corresponds to some of what goes on in the story:

${ }^{19}$ See Nelson (1949), Wansing (1993), Wansing (1998), Williamson (1993).

Australasian Journal of Logic (16:4) 2019, Article no. 1 


\begin{tabular}{|c|c|c|c|c|c|}
\cline { 2 - 6 } \multicolumn{1}{c|}{} & $w_{1}$ & $w_{2}$ & $w_{3}$ & $w_{4}$ & $w_{5}$ \\
\hline \hline Jones went to war & 0 & 0 & 0 & 0 & 0 \\
\hline Jones's ashes dispersed & - & 1 & 1 & 1 & 1 \\
\hline Widow falls asleep & - & - & - & 1 & 0 \\
\hline Jones was brave & - & - & - & - & - \\
\hline Jones was not brave & - & - & - & - & - \\
\hline
\end{tabular}

Both 1 and 0 project forward, because both of them record a constructive achievement (verification and falsification respectively) that is taken to be permanent. There is a third option, here represented by "“": a gap, a mere absence of either verification or falsification.

We now have to give separate clauses for $\Vdash_{1}$ and $\Vdash_{0}$ when defining the connectives:

$$
\begin{aligned}
& w \Vdash_{1} A \wedge B \text { iff } w \Vdash_{1} A \text { and } w \Vdash_{1} B \\
& w \Vdash_{0} A \wedge B \text { iff } w \Vdash_{0} A \text { or } w \Vdash_{0} B \\
& w \Vdash_{1} A \vee B \text { iff } w \Vdash_{1} A \text { or } w \Vdash_{1} B \\
& w \Vdash_{0} A \vee B \text { iff } w \Vdash_{0} A \text { and } w \Vdash_{0} B \\
& w \Vdash_{1} A \supset B \text { iff for all } x \geq w, x \Vdash_{1} A \text { or } x \Vdash_{1} B \\
& w \Vdash_{0} A \supset B \text { iff } w \Vdash_{1} A \text { and } w \Vdash_{0} B \\
& w \Vdash_{1} \neg A \text { iff } w \Vdash_{0} A \\
& w \Vdash_{0} \neg A \text { iff } w \Vdash_{1} A
\end{aligned}
$$

Negation is, unlike intuitionistic negation, an extensional connective that only concerns itself with the world at hand. In each and every world in our model, "Jones was brave" recives the gappy value "-", because it cannot be verified that he was brave. At the same time, in every world "Jones was not brave" receives also the gappy value "-", because "Jones was brave" can't be falsified. Just what we were hoping for, then.

Of course, other logics might be obtained by choosing other verification and falsification conditions for the connecitves, but I have argued in Kapsner (2014) that the clauses for Nelson logic are the most plausible ones, and will not repeat the argument here. The main point of this section is, in any case, not so much to argue for Nelson logic as much as showing that the story of Jones seems to point in some other direction than it was intended.

However, let me remark that there is one interesting distinction between intuitionistic and Nelson logic that seems pertinent to fiction: Nelson logic can, as intuitionistic logic cannot, plausibly be seen as a logic with truth value gaps ${ }^{20}$. In fact, one way to look at the matter is that Nelson logic is supplying a constructive interpretation for the connectives in the gappy logic K3 (see above)

${ }^{20}$ See Kapsner (2014) for discussion.

Australasian Journal of Logic (16:4) 2019, Article no. 1 
and adding a constructive conditional to it. Disregarding the conditional, the semantic clauses are equivalent to the matrix above, provided 1 is exchanged for $\mathcal{T}, 0$ for $\mathcal{F}$ and - for $\mathcal{N}$.

I am not aware of any elaborate attempt to base a theory of fiction on a constructive logic. It would seem a worhwhile project to look into this, pointed to by the very etymology of fiction: It comes from the Latin verb fingere, which means to shape, to mould, to make, which is pretty close to to construct. But instead of delving into this further, let us move on to the second example I want to discuss, which involves a mysterious box.

\section{Paraconsistency}

This story, called "Sylvan's Box" and summarized below, was written by Graham Priest as a response to critiques of paraconsistent logics. ${ }^{21}$ Paraconsistent logic allows us to formalize reasoning about contradictory situations, something that is impossible to achieve with classical logic. ${ }^{22}$ Critics such as David Lewis have argued that this isn't needed, as we cannot clearly reason about such situations at all. As an answer to this claim, Priest wrote a blatant inconsistency into his story: The box which gives it its title is both empty and not empty. ${ }^{23}$ (I will sum up the rest of the story in the next section).

Priest then proceeded to argue that it is clearly possible to reason about the content of the story, and that the logic that the reader has to adopt to grasp what is going on in the story cannot be classical, because that would lead the reader to infer things that are clearly not true in the story. As mentioned in the introduction, the problematic rule of inference is known as the Law of Explosion. It allows one to infer anything one wants from a contradiction, in symbols:

Law of Explosion $A \wedge \neg A \vDash B$

The invalidity of this rule is the defining feature of a paraconsistient logic. To again make the discussion somewhat concrete, I give one example of a paraconsistent logic. It is Priest's own Logic of Paradox (LP), arguably the best known paraconsistent logic (but by no means the only one). It is actually very similar to our first example logic, K3. The truth tables are just the same, with the only difference that the non-classical value $\mathcal{N}$ (neither-true-nor-false) is substituted by the value $\mathcal{B}$, which stands for both-true-and-false.

\footnotetext{
${ }^{21}$ Priest (1999).

${ }^{22}$ And in many non-classical logics, such as intuitionistic logic. Classical logic tends to be the main target in this debate, though.

${ }^{23}$ In a certain sense, the story is dual to the story about Jones. In that case, "not enough" was happening (nothing that could have told us whether Jones was brave or not. In this story, "too much" is happening (we both learn that the box is empty and that it isn't).
} 
LP:

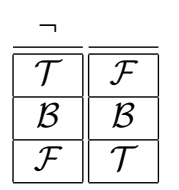

\begin{tabular}{|c|c|c|c|}
$\wedge$ & $\mathcal{T}$ & $\mathcal{B}$ & $\mathcal{F}$ \\
\hline \hline $\mathcal{T}$ & $\mathcal{T}$ & $\mathcal{B}$ & $\mathcal{F}$ \\
\hline $\mathcal{B}$ & $\mathcal{B}$ & $\mathcal{B}$ & $\mathcal{F}$ \\
\hline $\mathcal{F}$ & $\mathcal{F}$ & $\mathcal{F}$ & $\mathcal{F}$ \\
\hline
\end{tabular}

\begin{tabular}{|c||c|c|c|}
\hline$\vee$ & $\mathcal{T}$ & $\mathcal{B}$ & $\mathcal{F}$ \\
\hline \hline $\mathcal{T}$ & $\mathcal{T}$ & $\mathcal{T}$ & $\mathcal{T}$ \\
\hline $\mathcal{B}$ & $\mathcal{T}$ & $\mathcal{B}$ & $\mathcal{B}$ \\
\hline $\mathcal{F}$ & $\mathcal{T}$ & $\mathcal{B}$ & $\mathcal{F}$ \\
\hline
\end{tabular}

Formally, the only difference between $\mathrm{K} 3$ and LP is that $\mathcal{B}$ is treated as a designated value. Now, an easy counter model to $A \wedge \neg A \vDash C$ can be given by assigning $A$ the value $\mathcal{B}$ and $C$ the value $\mathcal{F}$.

Again, this is just for purposes of illustration. In arguing that the reader of "Sylvan's Box" does not infer anything whatsoever, Priest doesn't make any claims about LP in particular. He only claims to show that the reader is reasoning paraconsistently. In contrast to the first case study, I take this to be a highly successful strategy to motivate paraconsistency, and I will argue further below that it might even be more successful than Priest himself thinks.

\section{Sylvan's Box}

\subsection{The story}

Priest's largely (but clearly not wholly) autobiographical story goes as follows: After the sudden death of his long time friend and colleague, Richard Sylvan , Priest drives to Sylvan's remote home to start to work through his Nachlass. In between piles of papers he finds a little box with the words "Inconsistent Object" written on it. As he inspects it he finds the box, incredibly enough, both empty and not empty. Inside there is a little figurine and, at the same time, there is no figurine at all. This is not an optical illusion, the box is an object with perfectly contradictory properties. Priest and a friend discuss what to do with such a remarkable find, and they find themselves in two minds: they don't want to miss this chance of proving to the world that true contradictions exist, but neither do they want the box to fall into the wrong hands. ${ }^{24}$ The story ends on a truly inconsistent note: Priest takes the box with him when he leaves Sylvan's house, while the friend buries it in Sylvan's garden.

After this inconsistent ending, the reader is presented with a questionnaire that tests whether the reader has understood what is going on in the story. Priest then goes on to draw ten morals from this story about inconsistency, interpretation and the nature of impossible worlds and impossible objects. What is especially important for this piece is the following: The reader of Sylvan's Box can understand and reason about the story, even though it is inconsistent. Furthermore, she is lead to reason in a certain way, i.e., paraconsistently. ${ }^{25}$ This

\footnotetext{
${ }^{24}$ The story thus presaged the development of the WMTs (Weapons of Mass Trivialization) that by now seem like a plausible cause for humanity's ultimate demise.

${ }^{25}$ Paraconsistency, i.e. the invalidity of Explosion, is not to be confused with dialetheism, a metaphysical doctrine also defended by Priest. According to dialetheism, there are true
} 
can be seen by looking at her answers to the questionnaire; she would have been wrong to reason in a different way. For example, if she concluded via Explosion that the box was shot off to the moon in the end of the story, she would not have read the story correctly.

However, neither would she have understood what was going on by following David Lewis's suggestion how to deal with inconsistent bodies of information in Lewis (1982). Here, the idea would be to break up the story into (maybe maximally) consistent chunks and only draw inferences from those. But that way the reader would not only miss the whole point of the story, she would be drawing false inferences. Asked why Priest was so excited in the story, she would have to either answer it was because he found the box to be empty, or alternatively answer that it was because the box wasn't empty. But neither is right, Priest was excited because the box was both empty and not empty. ${ }^{26}$

\subsection{Lewis's reaction to the box}

To be fair, Lewis had in mind everyday cases of mistaken beliefs leading to inconsistent belief sets, and he never meant to suggest that strategy in the case of obviously contradictory stories. His position in his paper "Truth in Fiction" was that

"anyhing whatever is vacuously true in an impossible fiction. That seems entirely satisfactory if the impossibility is blatant: if we are dealing with a fantasy about the troubles of the man who squared the circle, or with the worst sort of incoherent time-travel story. We should not expect to have a non-trivial concept of truth in blatantly impossible fiction [...]" (Lewis (1978), p.275)

Sylvan's Box, however, had the effect of forcing Lewis to change his mind, as is evidenced by this quote from a letter he wrote to Priest (reprinted in Priest et al. (2004), p.176):

"I'm increasingly convinced that I can and do reason about impossible situations. ("Sylvan's Box" played a big part in persuading me.)"

He does not go so far as admitting that the logic one has to employ in reasoning about stories such as "Sylvan's Box" has to be paraconsistent, though. He picks

contradictions. Of course, the story is as little proof of dialetheism as Doyle's stories prove the existence of Holmes, but proving dialetheism is not at all the aim of the story.

${ }^{26}$ In his paper, Lewis discusses an idea that is closely related to what amounts to the dual of supervaluationism (see above), what has later been christened subvaluationism. A subvaluation consideres all the ways in which a glutty valuation can be made consistent by assigning either $\mathcal{T}$ or $\mathcal{F}$ to all those which have received value $\mathcal{B}$ in the original valuation. The idea has little merit here, for just the reasons pointed out in the preceding paragraph. 
up the distinction between "blatant" and "subtle" impossibilities he had made earlier and argues that the issue of paraconsistency only arises in connection with blatant impossibilities. Even though he himself admits to be very unclear about the distinction, he must have been taking the impossibility of "Sylvan's Box" to be a subtle one, because he calls the mention of paraconsistency here "off the topic". Had it not been for his untimely death, he might have worked his view out more fully, but as it stands I have to say I can't see in what way the inconsistency of "Sylvan's Box" is not blatant, and neither can I fathom how, as a logician, one might appreciate the intuitive thrust of the story and not take it to be about paraconsistency.

\section{Story-Inducable Logics}

Now, one might be tempted to make all this into a very strong argument for paraconsistent logic. At the very least, we have to be able to employ a paraconsistent logic to deal with this story, and we don't seem to have much of a problem with that. If the logic we are employing is not paraconsistent from the outset, then it seems strange that we can make the transition so easily.

Interestingly, Priest actually doesn't take that line of argument. He seems to suggest that for any logic whatsoever, a story could be told that would make it seem the only suitable logic for this story. That is what he did with Sylvan's Box for paraconsistent logic, and he suggests one could write a story to get the reader to reason along the lines of quantum logic.

The point he is making echoes Richard Sylvan himself, who, then still under the name Richard Routley, wrote that "the logic of a fictional world may be any logic" 27 . In a sense, Priest proved one instance of this hypothesis by writing his story.

It is interesting to follow Routley's hypothesis further through and and investigate what kinds of logic can be forced onto the reader in a similar way by writing actual stories. I will write that a story induces a given logic when this kind of maneuver succeeds. What would a story look like that induces fuzzy logic, or one that induces a substructural logic? I think these are fascinating questions, but in this section I'd like to experiment with a seemingly easier case, namely classical logic. Is there a story to be told to a paraconsistentist or a constructivist that would get him to reason classically about what is going on in the story?

\footnotetext{
${ }^{27}$ Routley (1979), p.10 See Proudfoot (2018) for an excellent discussion of this paper and the further developments in Routley (1980).
} 


\section{Inducing Classical Logic (I): Explosion}

We will start with the case of paraconsistency Again, the interesting difference between classical logic and a paraconsistent one is that classical logic validates Explosion, the principle that from a contradiction any proposition whatsoever follows. So let's see how one would go about telling a story that induces a logic that validated Explosion. In the dispute with the constructive logician, the task would be to construct a story that induces the Law of Excluded Middle. We will turn to that later.

\subsection{The indirect Strategy}

One way would be to tell a consistent story that exhibits typical inferential moves that paraconsistent logicians are traditionally having trouble with, such as Disjunctive Syllogism $(A, \neg A \vee B \vDash B)$ and Modus Ponens $(A, A \rightarrow B \vDash B)$. To illustrate, observe that Disjunctive Syllogism is not valid in LP, and the same is true if we add a defined conditional to LP in the usual way. In a second step of the attack, the defender of Explosion would challenge the paraconsistentist to come up with a workable logic that validated all the inferences drawn in the story and didn't validate Explosion.

Even though Priest hasn't made any suggestion about which logic in fact is employed by the readers of his story, we might speculate that he would endorse his LPm in face of such an attack. LPm is introduced in the second edition of his In Contradiction (Priest (2006)), and is an improved version of LP. While LP might in fact be outmaneuvered by a suitably constructed story, ${ }^{28} \mathrm{LPm}$ can (arguably) deal with those challenges.

\subsection{The direct strategy}

More satisfactory, in any case, for the classical logician would be to come up with a story that induces Explosion directly. What we want is a story that makes the reader infer everything. To test this we might give him a questionnaire much like Priest (hypothetically) did. Some care has to be taken with the phrasing of the questions, however. If a question is, e.g., "Can pigs fly in the story", the answer we would hope for would be "Yes". But even if we succeeded in making the reader infer everything, he might still answer "No", meaning that in the story pigs cannot fly, which of course should also be true. Therefore, let's only ask questions of the form "Is it true in the story that X". Whatever X may be (and we should include a wide variety of propositions in the questionnaire), we should hope for the answer "Yes" and nothing else.

But even if we get the reader to check the "Yes" box after every question. we cannot be sure to have succeeded in inducing Explosion. We have to make

\footnotetext{
${ }^{28}$ Though the proof of that has not yet been given, as the story has not yet been told.
} 
sure that the only way to conclude that every answer to the questions is "Yes" is indeed by way of the principle of Explosion. Take the minimal (or rather maximal) "story":

Everything is true.

Of course, the answers to our questions about this story will come out "Yes", but Explosion is neither the only nor the most straightforward way to infer these answers. We have to come up with something more refined.

\subsection{Three Attempts}

One thing is clear: The story has to sport an inconsistency, and probably a quite blatant one at that. We already have such a story to work with, namely Sylvan's Box. Let's try to turn it into a story inducing Explosion.

As Explosion tells us that anything follows from a contradiction, one might simply try to append all kinds of random statements to the story. E.g.:

Alternative Ending 1:

"As I [i.e. Priest, the story is told from the first person perspective] drove down into town with the box in the trunk of my car, I came about a flock of pigs flying around my car, and the moon was made of green cheese. To my further surprise I realized that the sum of five and seven was fourteen. And eleven as well."

Append enough of these, and a logician might get what is meant to be going on, but surely this isn't much more than an insider joke. It's another interesting project to construct stories such that a trained logician could find out what logic is meant to be characterized. But such a logical detective story is not what we are after. We want a story that makes logicians and laymen alike infer classically. No layman reading the story would take those statements to be conclusions of the former contradiction. The reason is simply that one cannot make statements be taken as consequences of each other simply by writing them in sequence.

Then what does it take to turn a series of statements in a story into a logical consequence from premises to conclusions? Well, at this point I have to say that I can't think of any other way to pull this off than to state the aim outrightly, for example thus:

Alternative Ending 2:

"As I drove down into town, I checked the contents of the box again. Sure enough, it was still empty. And sure enough the box still contained the little figurine. Therefore, a flock of pigs turned up on the horizon and flew towards me, soon to be circling around my car." 
I suggest that this strategy will not be successful. To my mind, the problems it runs into are the same that the literature knows under the name "imaginative resistance". In short, the reader, even if she has swallowed all that preceded the last sentence, is not likely to buy this last part. It's not that pigs can fly that she can't accept, but rather that this is supposed to be a logical consequence of the preceding contradiction. It's exactly the "therefore" that will upset her reading experience. It may be that she just isn't sure what the "therefore" is meant to express here, as one isn't accustomed to reading something like that in a short story. One may try to elaborate to get the point through:

Alternative Ending 3:

"As I drove down into town, I checked the contents of the box again. Sure enough, it was still empty. And sure enough the box still contained the little figurine. This was clearly contradictory, and I knew what I had to expect to happen. It's a logical truth that everything follows from a contradiction. And so it was with horror, but without real surprise that I saw a flying pig that was about to hit my windshield."

I submit that this isn't much better. I'm not sure that it is possible to tell a truly trivial story (one in which everything is true) that the reader can engage with, but in any case I think she will resist the claim that everything is to be inferred from the earlier contradiction. ${ }^{29}$ And any "normal" attempt to motivate Explosion further will fail, because it will need to invoke the principle that a contradiction is never true, which is clearly violated in any inconsistent story from the outset.

Of course, these attempted alternative endings won't make for the most engaging literary experience. After all, much of the persuasive strength of Sylvan's Box lies in it's being a well written short story. However, no matter how well crafted one's story might be, I don't see how the reader can be made to draw explosive inferences without the narrator telling him to, and I think in every such case a feeling of resistance will be felt, a feeling I will inspect more closely in the next section.

\section{Imaginative Resistance}

The term "imaginative resistance" came up in the discussion about the problems that arise in relating deviant morality or humor in stories. A story might have a mob of outraged commuters killing a couple that is clogging up traffic on the freeway. (This example is the story that Brian Weatherson tells to illustrate

\footnotetext{
${ }^{29}$ The same goes for the examples in Wildman and Folde (2017), in which the validity of Explosion is part of the story. See also Estrada González (2018) for more discussion of these examples.
}

Australasian Journal of Logic (16:4) 2019, Article no. 1 
the phenomenon in Weatherson (2004)). It's no problem at all to tell this in a way that engages the reader enough to have him "buying" it, i.e. to get him to hold the given events as true in the story. However, it is very hard indeed to do the same with a moral judgment about the situation. Just because the narrator tells you that the mob was right to kill the couple doesn't make it true, not even true in the story. The reader's imagination will revolt at that point, hence the name "imaginative resistance". In Weatherson's words, "we refuse, fairly systematically, to play along with the author here."(Weatherson (2004), p.2)

The same is said to hold in he case of humor. There is no problem in having a character tell a joke that is not funny, but it's hard to then make it part of the story that it actually is funny. It is far from clear what the reason for these refusals of cooperation on the part of the reader is, and none of the attempts to explain the phenomenon in the literature is wholly convincing. Personally, I take the accounts that focus on the role of the narrator to be the most promising. In cases of imaginative resistance, the narrator suddenly becomes a salient agent, and moreover one who has overstepped the boundaries of his role. The narrator is supposed to relate the factual events of a given story, and is not supposed to give moral judgements or decide wether a joke is funny or not. A good illustration likens the narrator of a story to a foreign correspondent reporting from a distant country. As long as that person sticks to the facts, he is in a much better epistemic position than we are, and we tend to believe him as long as we have no independent reason to doubt his words. As soon as he starts to dish out moral judgements, though, he is not in a better position than we, and we react with a sense of "Well, that may be what you think, but I beg to differ!". We pride ourselves to be able to make our own moral judgements, and we don't like to be told what to think in these matters, neither by a foreign corespondent nor by the narrator of a fictional story.

What I'd like to suggest is that the weirdness of the examples I gave above is of the same kind as the cases where deviant moral judgements or divergent senses of humor are attempted to be pushed onto the reader. I think that the reader of one of my proposed stories will respond in exactly the same way as the reader of Weatherson's story about the avenging commuter. He might accept all that happens factually, but when it comes to judging what follows from what, he will insist on doing the inferring for himself and reject any inferential moves the narrator makes that he wouldn't accept to be valid outside of the story, as well.

Now, the following observation is as important as it is obvious: It is of course only when the moral judgements of the narrator clash with our own that we resist them. If Weatherson's narrator had gone on to tell us that it was wrong of the man to kill two people just because they were causing a traffic jam, it might have struck us as a strange bit of storytelling. However, we wouldn't have resisted the judgement and concluded that the murder was in fact justified, just because we don't like to be told what to think. That would be a bit juvenile, after all.

Australasian Journal of Logic (16:4) 2019, Article no. 1 
If the case of logical resistance indeed is of the same sort as the other kinds, then it would be hard for anyone to argue that a logic that we feel imaginative resistance toward is actually the one that we employ outside of story-reading. If one presented this argument, the parallel to the phenomenon described in the last paragraph would break down. Logic would be the only case I know of in which something like this is happening, and I see no reason to suppose such exceptionality.

To sum up this section, I take it to be a further challenge (i.e., going beyond Priest's original point) for the classical logician to explain why not only we seem to be perfectly able to reason paraconsistently, but why we moreover don't like to be told to reason classically. And if I am right and a feeling of resistance is the appropriate reaction to the last ending I proposed, I furthermore do not see how classical logic, or more narrowly Explosion, could be induced.

\section{Inducing Classical Logic (II): Law of Excluded Middle}

Now, let us at this point go back to the first principle we talked about. What kind of story could the classical logician tell that would induce the Law of Excluded Middle?

The situation seems to me to be quite parallel to the one explored above: The classical logician could try an indirect strategy and home in on inferences that seem unrelated to the Law of Excluded Middle, but that the constructive logicians have trouble with. Nelson logic, which I mentioned above, has its own problems, and thus weaknesses to exploit for the classical logician. To take one prominent example, in this logic contraposition fails. In order to get mileage out of this, the story would have to contain a conditional (outside of direct speech), which is a bit unusual. I don't deny that it can be done, ${ }^{30}$ but I think it will be a challenge.

Again, though, this would not exactly be a knock out punch. It might just mean that some part of the logic away from the Law of Excluded Middle should be tinkered with, probably the conditinal. What about the prospects of the direct strategy, a story that somehow forces the reader to assume the Law of Excluded Middle as a matter of logical truth?

Listing a long sequence of instances of the Law obviously has no effect, as there would not be the faintest motivation for the reader to run some form of induction on this to reach the conclusion that the Law must be always true, let alone logically valid in this story. So, it seems that the only chance is to tell the reader outright what we want them to think, as above:

\footnotetext{
${ }^{30}$ Maybe the first line of Pride and Prejudice is best analyzed as a conditional:

"It is a truth universally acknowledged that a single man in possession of a good fortune must be in want of a wife."
}

Australasian Journal of Logic (16:4) 2019, Article no. 1 
"[Story about Jones]

But Jones was brave, or he wasn't - after all, this is a law of logic."

In fact, this might indeed work better than the corresponding attempt for Explosion, if only because the Law of Excluded Middle has a much more sane ring to it. It might actually be worthwhile to do an empirical study on whether this would elicit imaginative resistance or not.

\section{What Can be Learned}

I think that the stories we looked at open up an alluring field of research. It would be very intersting to see which accounts of negation, and further what kinds of logics can be induced by appropriately designed stories.

At the least, it seems that this is not possible for any logic, and thus, that Routley's hypothesis on page 8 is false. We've seen an example in which the induced logic seems not to be what the author of the story intended it to be, and an example in which the author succeeded, and where his opponents seem to be unable to come up with an equally compelling story. Even if we might be logical pluralists ${ }^{31}$, the exercise seems to show that not every logic is created equal when it comes to story-inducability. I take this to be a point against those logics which aren't inducable.

In fact, it makes more sense to talk about the uninducable logics rather than the inducable ones, as I don't see a clear way to force a single particular logic on a reader. We seem to be dealing with a rather Popperian enterprise, in that we can devise stories that speak against certain principles like the Law of Excluded Middle or Explosion. This rules out a host of logics, but it does not unequivocally point to a single logic. The example logics I talked about in the course of this essay were just that, plausible examples from the class of logics a particular story has not ruled out.

However, it seems to be a fair question whether there can be even a single logic that can survive multiple story-based attacks. ${ }^{32}$ If there isn't, the project seems to point toward a logical pluralism that leaves unclear how any logic can be definitively ruled out by a fiction: The most that can be said that this is not the right logic for this particular fiction. I can't settle that question for every fiction, of course, but I can give an example of a logic that can deal with both literary phenomena discussed in this piece.

\footnotetext{
${ }^{31}$ What should the logical monist make of all this, you ask? I have shown elsewhere that there are ways to combine constructivity and paraconsistency (see Kapsner (2014)), but that is a story for another day.

${ }^{32}$ Routley obviously believed this, as it follows rather trivially from his hypothesis that any logic can be induced by a suitable logic. But, of course, it might be true even if I am right in rejecting this universal hypothesis.
}

Australasian Journal of Logic (16:4) 2019, Article no. 1 
There is a paraconsistent variant of the Nelson logic I introduced above called $N_{4}$. The logic $N_{4}$ allows $v$ to assign 1,0 , neither or both values to a statement at a world. That is, we are not dealing with a valuation function any more, but with a valuation relation. This is the only difference between the two logics, but it is enough to invalidate Explosion. A one-world model in which $A$ takes both value 1 and 0 , and $\mathrm{B}$ takes only value 0 is enough to show that $A \wedge \neg A \Vdash B$.

Let's see a model for a story that splices our two story-lines together: After Jones's death, his widow finds Sylvan's box hidden among his possessions. How he came to it is left open by the fiction, but the box behaves just as inconsistently as in Priest's original story.

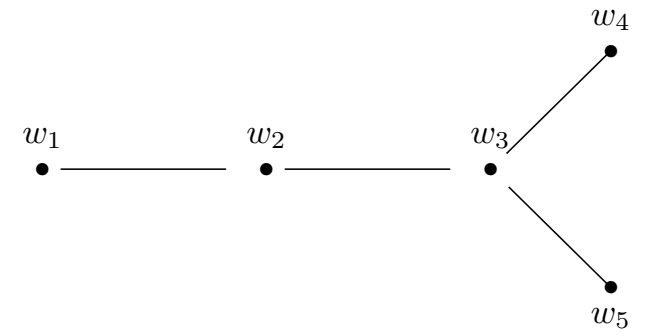

Here is a valuation that suits the requirements of $N_{3}$ and corresponds to some of what goes on in the story:

\begin{tabular}{|c|c|c|c|c|c|}
\cline { 2 - 6 } \multicolumn{1}{c|}{} & $w_{1}$ & $w_{2}$ & $w_{3}$ & $w_{4}$ & $w_{5}$ \\
\hline \hline Jones went to war & 0 & 0 & 0 & 0 & 0 \\
\hline Jones was brave & - & - & - & - & - \\
\hline Widow finds Box & - & 1 & 1 & 1 & 1 \\
\hline Box is Empty & - & - & 1,0 & 1,0 & 1,0 \\
\hline Widow moves to Australia & - & - & - & 1 & 0 \\
\hline
\end{tabular}

Inconsistent things are true in this story, but that does not mean that everything is true in it. Some things are true, and some are false. Some things that are neither true nor false might become settled if the story were extended, such as the question whether Jones's widow moved to Australia later in her life. And some other things, such as "Jones was brave", will remain neither true nor false, no matter how the story is extended.

The model above is in accordance with these thoughts. However, I don't mean to suggest that Nelson logic is the only way to make formal sense of the phenomena I've discussed. Although I like the Nelson logics for a host of reasons going beyond the material in this paper, I would not be surprised if stories could be constructed that gave them troubles of their own. What I do want to suggest is that there is, in general, something useful that we can learn about logic from fiction, and, in particular, that the Law of Excluded Middle and the Law of Explosion seem a little more suspect after the study of the stories we have looked at.

Australasian Journal of Logic (16:4) 2019, Article no. 1 
As a last resort, one might argue on behalf of the classical logician for yet another sort of logical pluralism invovling two different logics: Namely, one might want to say that fiction might have its own logic, distinct from our everyday logic. Stories, one might hold, need a weaker notion of logical consequence, just because more things are possible in a story than in real life. Maybe we need something like $N_{4}$ for stories, but outside of fiction we can't go wrong with classical logic.

In part, this would mean that one would bite the bullett and claim that the parallel I pointed out on page 153 would indeed break down. As I explained there, I don't find that very plausible, but still, this might have some traction against Priest's story. ${ }^{33}$ It would not be quite as effective against the story of Jones, which, unlike Sylvan's Box, could well be a true story.

Again, I'm sure there are many more things that might be said against this argument on behalf of the classicist. For this piece, however, a development that would be at least as interesting as digging deeper into that debate would be if a classical logician took up the challenge and constructed a story that succeeded where I have failed, i.e. in inducing Excluded Middle and Explosion. ${ }^{34}$

\section{Acknowledgements}

This paper has received a lot of helpful feedback over the years. I received particularly helpful comments at the conferences Logic in Bochum 2 (Raesfeld) and Falsity II (London). In the latter case, Simon Hewitt gave a commenting talk, for which I am especially grateful. Other useful comments were given by Graham Priest, Genoveva Marti, Sven Rosenkranz and Heinrich Wansing. I would also like to thank an anonymous reviewer for very helpful comments and criticism. As a result, the paper has improved much. It has also become somewhat more partisan, as the revision has made me voice my opinions where I was more non-committal in the draft. I hope it still transpired that my main intention, however, was not so much to make a case for a particular logic, but to illustrate how stories can be used to make such cases. Lastly, the editor of this journal has given me some helpful pointers for which I am grateful.

\footnotetext{
${ }^{33}$ Though it would do nothing to substantiate the stronger claim that paraconsistent logics are inherently useless, in fact it seems to undermine that claim. Paraconsistent features would at the very least be required to describe the story logic.

${ }^{34}$ To be clear, I mean to challenge the classicists to induce these principles directly. The reviewer suggested at this point that a good chance for the classicist lied in an indirect strategy, such as explored in 9.1. That is, she might try to point to apparently valid forms of argument such as disjunctive syllogism as surrogates for the Law of Explosion. The best way to respond to this, on behalf of the non-classicist, seems to be to either construct a story to invalidate disjunctive syllogism, or to presents a logic that retains it without also validating the Law of Explosion.
} 


\section{References}

Achourioti, T., Fugard, A. J., and Stenning, K. (2014). The empirical study of norms is just what we are missing. Frontiers in psychology, 5 .

Badura, C., Berto, F. (2019). Truth in fiction, impossible worlds, and belief revision. Australasian Journal of Philosophy, 97(1), 178-193.

Berto, F., Jago, M. (2019). Impossible worlds. Oxford University Press.

Crossley, J., and Dummett, M. (eds.) (1965). Formal Systems and Recursive Functions, Amsterdam, North-Holland Publishing.

Dummett, M. (1978). Truth and other enigmas. Harvard University Press.

Estrada González, L. (2018). (In Some Fictions) Everything is True. The Australasian Journal of Logic, 15(2), 64-76.

Hanley, R. (2004). As Good As It Gets: Lewis on Truth in Fiction. In Jackson and Priest (eds.), Lewisian Themes, Oxford, Oxford University Press.

Kapsner, A. (2014). Logics and Falsifications. Springer.

Kripke, S. (1965). Semantical analysis of intuitionistic logic. In J. Crossley and M. A. E. Dummett (eds.) (1965): 92-130.

Lewis, D. (1982). 'Logic for Equivocators', Noûs, Vol. 16, No. 3., pp. 431-441.

Lewis, D. (1978). Truth in Fiction. American Philosophical Quarterly 15 (1): $37-46$.

Nelson, D. (1949). Constructible falsity. Journal of Symbolic logic, 14/1:16-26.

Priest, G., Beall, J., and Armour-Garb, B. (eds.) (2004). The Law of NonContradiction: New Philosophical Essays, Oxford University Press.

Priest, G. (1999). Sylvan's Box: A Short Story and Ten Morals. Notre Dame Journal of Formal Logic 38(4): 573-582, 1999

Priest, G. (2006). In Contradiction, Second Edition, Oxford University Press.

Priest, G. (2008). Introduction to Non-Classical Logic, 2nd edition, Cambridge University Press.

Proudfoot, D. (2018). Sylvan's Bottle and other Problems. The Australasian Journal of Logic, 15(2), 95-123.

Routley, R. (1979). The semantical structure of fictional discourse. Poetics, 8(1-2), 3-30.

Routley, R. (1980). Exploring Meinong?s Jungle and Beyond: An Investigation of Noneism and the Theory of Items (Interim edition). Departmental Monograph No. 3, Philosophy Department, Research School of Social Sciences, Australian National University.

Australasian Journal of Logic (16:4) 2019, Article no. 1 
Varzi, A. C. (1997). Inconsistency without contradiction. Notre Dame Journal of Formal Logic, 38(4), 621-639.

Wansing, H. (1993). The logic of information structures. Lecture notes in AI 681, Berlin, Springer.

Wansing, H. (1998). Displaying modal logic. Dordrecht, Kluwer Academic Publishers.

Weatherson, B. (2004). Morality, Fiction, and Possibility. Philosopher's Imprint vol. 4, no. 3, pp. 1-27, 2004

Wildman, N., Folde, C. (2017). Fiction unlimited. The Journal of Aesthetics and Art Criticism75(1): 73-80.

Williamson, T. (1994a). Never say never. Topoi, 13(2), 135-145.

Williamson, T. (1994b). Vagueness. Routledge.

Woods, J. (2009). The Logic of fiction. College Publications. 